\title{
Metal-Organic Framework-Derived Hybrid $\mathrm{Co}_{3} \mathrm{O}_{4}$-Carbon Porous Nanowire Arrays as Reversible Oxygen Evolution Electrodes
}

\author{
Tian Yi Ma, ${ }^{\dagger}$ Sheng Dai ${ }^{\dagger}{ }^{\text {Mietek Jaroniec }}{ }^{\ddagger}$ and Shi Zhang Qiao*,† \\ † School of Chemical Engineering, The University of Adelaide, Adelaide, SA 5005, Australia \\ ‡ Department of Chemistry and Biochemistry, Kent State University, Kent, Ohio 44240, USA \\ KEYWORDS: metal-organic framework, hybrid $\mathrm{Co}_{3} \mathrm{O}_{4}$-carbon, nanowire array, pore, oxygen evolution reaction
}

\begin{abstract}
Hybrid porous nanowire arrays composed of strongly interacting $\mathrm{Co}_{3} \mathrm{O}_{4}$ and carbon were prepared by a facile carbonization of the metal-organic framework grown on $\mathrm{Cu}$ foil. The resulting material, possessing a high surface area of $251 \mathrm{~m}^{2} \mathrm{~g}^{-1}$ and a large carbon content of $52.1 \mathrm{wt} . \%$, can be directly used as the working electrode for oxygen evolution reaction without employing extra substrates or binders. This novel oxygen evolution electrode can smoothly operate in alkaline solutions (e.g. $0.1 \mathrm{M}$ and $1.0 \mathrm{M} \mathrm{KOH})$, affording a low onset potential of $1.47 \mathrm{~V}(v s$. reversible hydrogen electrode) and a stable current density of 10.0 $\mathrm{mA} \mathrm{cm}{ }^{-2}$ at $1.52 \mathrm{~V}$ in $0.1 \mathrm{M} \mathrm{KOH}$ solution for at least 30 hours, associated with a high Faradaic efficiency of $99.3 \%$. The achieved ultrahigh oxygen evolution activity and strong durability, superior performance as compared to the state-of-the-art noble-/transitionmetal and non-metal catalysts, are originated from the unique nanowire array electrode configuration and in situ carbon incorporation, which lead to the large active surface area, enhanced mass/charge transport capability, easy release of oxygen gas bubbles and strong structural stability. Furthermore, the hybrid $\mathrm{Co}_{3} \mathrm{O}_{4}$-carbon porous nanowire arrays can also efficiently catalyze oxygen reduction reaction, featuring a desirable four-electron pathway for reversible oxygen evolution and reduction, which is potentially useful for rechargeable metal-air batteries, regenerative fuel cells and other important clean energy devices.
\end{abstract}

\section{INTRODUCTION}

Growing energy demands have stimulated a considerable interest in alternative energy conversion and storage systems such as metal-air batteries, water splitting devices and fuel cells, which are all closely associated with a core process, oxygen evolution reaction (OER) that is initiated at the boundary of multiple phases (solid, liquid, gas). ${ }^{1}$ To rationally design the reaction interface for OER, an optimal electrode structure involving high-performance catalysts is essential in reducing the overpotential, promoting the reaction kinetics and enhancing the specific activity for OER, thus improving the energy efficiency. ${ }^{2}$ However, most of the reported OER electrocatalysts, such as noble-metal (Ir, Ru), ${ }^{3}$ transition-metal ( $\mathrm{Co}$, $\mathrm{Mn}, \mathrm{Ni}, \mathrm{Fe}$, etc. $)^{4}$ and non-metal catalysts (graphitic carbon nitrides, N-doped graphitic carbons, etc.), ${ }^{5}$ are generally prepared in the form of thin films or particle agglomerates coated onto glassy carbons, nickel foams or other conductive substrates. In most cases, these fabrication techniques require time-consuming film casting or coating procedures with assistance of polymeric binders, which result in uncontrolled micro-structure of the obtained electrodes featuring limited catalytically active surface areas that are unfavorable for electron conductivity and multiphase reactant/product transport during OER (e.g. $\mathrm{OH}^{-}$in liquid phase, $\mathrm{O}_{2}$ in gas phase). Also, the easy peeling of the coated catalysts from the electrodes during evolution of a large amount of $\mathrm{O}_{2}$ greatly impairs their electrocatalytic activity and shelf life. ${ }^{6}$ Thus, the development of alternative electrode configurations for efficiently catalyzed
OER with high activity and strong long-term stability is urgently needed.

Recently, the well-aligned nanowire arrays with catalytically active components directly grown on the current collectors have been considered as a new generation of highly effective electrodes due to their intrinsic advantages. ${ }^{7}$ The open space within nanowire arrays facilitates the electrolyte penetration and diffusion of ionic species, allowing high utilization efficiency of active species. The direct contact of nanowire arrays with the underneath conductive current collectors and their strong binding assure good electrical conductivity between them, as well as high structural stability of the obtained electrodes. ${ }^{6 b, c, 7,8}$ Thus, these electrodes show great potential for direct use in electrochemical cells, and they are particularly beneficial for OER that involves continuous evolution of $\mathrm{O}_{2}$ gas. ${ }^{1,3-5}$

Nevertheless, the use of nanowire arrays for electrocatalytic OER is still in its infancy. Only a few illustrations including $\mathrm{Zn}_{x} \mathrm{Co}_{3-x} \mathrm{O}_{4}$ and $\mathrm{Ni}_{x} \mathrm{Co}_{3-x} \mathrm{O}_{4}$ nanowire arrays grown on Ti foils, ${ }^{9}$ $\mathrm{Co}_{3} \mathrm{O}_{4}$ nanowire arrays grown on the stainless steel meshes, ${ }^{10}$ and $\mathrm{Ni}$-substituted $\mathrm{Co}_{3} \mathrm{O}_{4}$ nanowire arrays grown on $\mathrm{Ni}$ foams ${ }^{11}$ were reported, all focusing on $\mathrm{Co}_{3} \mathrm{O}_{4}$-based spinel materials due to their good catalytic activity and corrosion stability toward electrochemical OER in alkaline media. ${ }^{12}$ Their fabrication unexceptionally involved nucleation and growth of inorganic precursors on certain substrates, and was limited to pure metal oxides. ${ }^{9-11}$ However, the semiconducting metal oxide nanowires having the length of several micrometers do not assure a continuous pathway for electron transport along them. ${ }^{7}$ Also, the mass transport and accessible catalytically active sites associated with individual nanowires are 
limited due to the low porosity and relatively small surface area of the nanowires. ${ }^{9-11}$ Therefore, further improvement of this type of electrodes is highly expected, especially through increasing the electrical conductivity of single nanowires by elemental doping or other methods, and through introducing accessible pores into the nanowires.

To achieve these goals, we design the first hybrid $\mathrm{Co}_{3} \mathrm{O}_{4-}$ carbon porous nanowire arrays (denoted as $\mathrm{Co}_{3} \mathrm{O}_{4} \mathrm{C}-\mathrm{NA}$ ), which are prepared by carbonization of the metal-organic framework (MOF) directly grown on $\mathrm{Cu}$ foil in $\mathrm{N}_{2}$ atmosphere. The periodic arrangement of metal nodes and organic motifs in MOF scaffolds leads to a homogeneous distribution of metal oxide nanoparticles and in situ formed carbon species. Our purpose is to accomplish better catalytic performance of the hybrid nanowire array electrode by combining distinctive properties of metal oxide and carbon components, and taking advantage of their uniform distribution and synergy. ${ }^{13}$ Herein, the use of Co-based $\mathrm{MOF}$ as the precursor represents a facile way of obtaining $\mathrm{Co}_{3} \mathrm{O}_{4} \mathrm{C}-\mathrm{NA}$ with the high surface area and large carbon content. Remarkably, $\mathrm{Co}_{3} \mathrm{O}_{4} \mathrm{C}-\mathrm{NA}$ not only exhibits better oxygen evolution activity and stronger durability than most of the highly active noble-/transition-metal and nonmetal catalysts reported to date, but also efficiently catalyzes the reverse oxygen reduction reaction (ORR). Its outstanding activity can be attributed to the large active surface area, favorable charge and mass transport in the stable nanowire array electrode structure.

\section{RESULTS AND DISCUSSION}

\subsection{CATALYST SYNTHESIS CHARACTERIZATION}

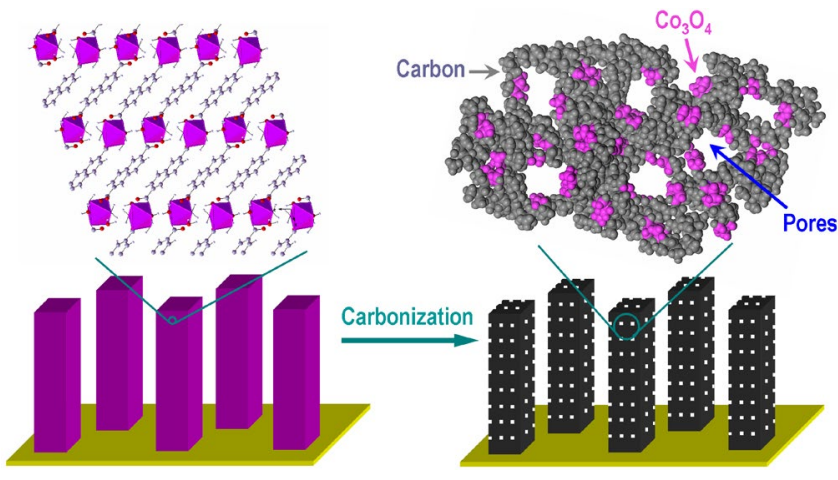

Scheme 1. Fabrication of hybrid $\mathrm{Co}_{3} \mathrm{O}_{4}$-carbon porous nanowire arrays.

The hybrid $\mathrm{Co}_{3} \mathrm{O}_{4}$-carbon porous nanowire arrays were synthesized from a Co-naphthalenedicarboxylate MOF with layered crystalline structure used as the precursor (Scheme 1), which was directly grown on $\mathrm{Cu}$ foil through a lowtemperature $\left(80^{\circ} \mathrm{C}\right)$ hydrothermal process. Next, the inorganic and organic components in the MOF were converted, respectively, into $\mathrm{Co}_{3} \mathrm{O}_{4}$ and carbon via carbonization in $\mathrm{N}_{2}$ atmosphere, which resulted in the formation of hybrid nanowires with simultaneously generated pores inside.

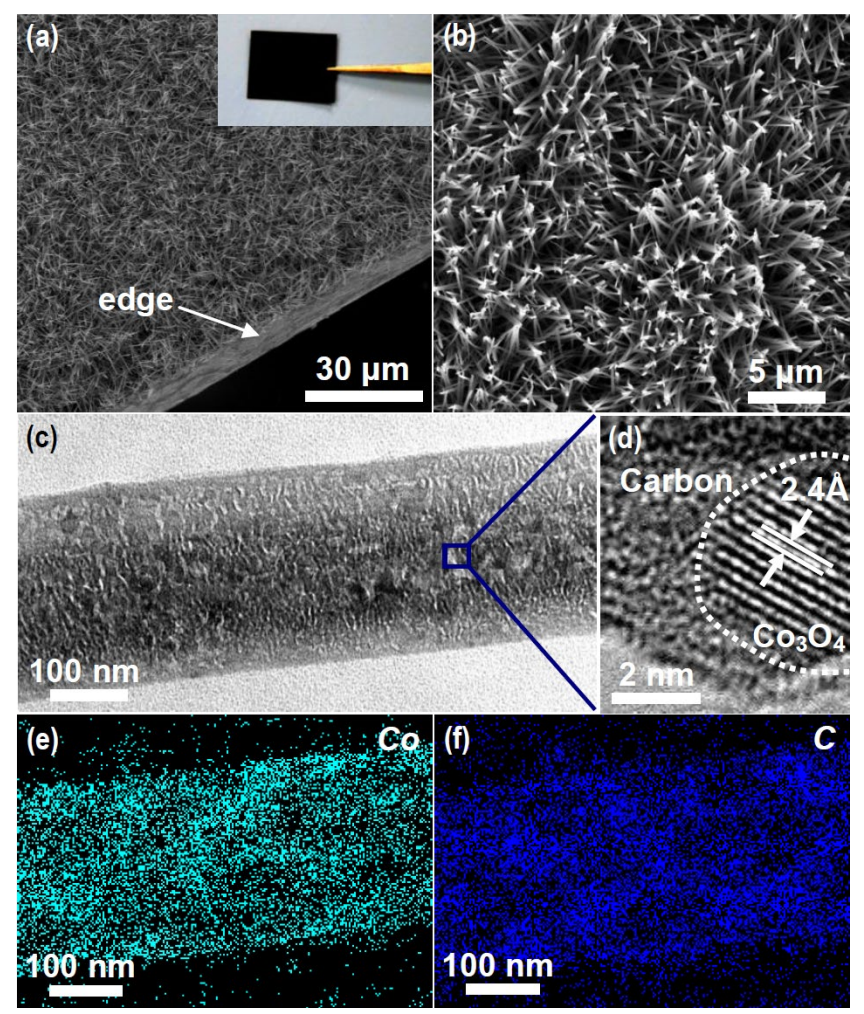

Figure 1. (a, b) SEM, (inset in panel a) optical image, (c) TEM, (d) HRTEM, and (e, f) EDS elemental mapping images of $\mathrm{Co}_{3} \mathrm{O}_{4} \mathrm{C}-\mathrm{NA}$.

Nanowire arrays of $\mathrm{Co}_{3} \mathrm{O}_{4} \mathrm{C}-\mathrm{NA}$ (scanning electron microscopy (SEM), Figures 1a, b), preserving the morphology of the Co-based MOF (Figure S1, Supporting Information), grow on the surface of $\mathrm{Cu}$ foil, the color of which turns to black (Figure 1a inset). A single nanowire with smooth surface and the diameter of $\sim 250 \mathrm{~nm}$ is observed in the transmission electron microscopy (TEM) image (Figure 1c). Nanowires obtained with high yield and without presence of morphologically different particles and their smooth surface indicate that all $\mathrm{Co}_{3} \mathrm{O}_{4}$ and carbon species are well integrated inside them with negligible amount of isolated $\mathrm{Co}_{3} \mathrm{O}_{4}$ nanocrystals. Numerous slit-like pores visible throughout the nanowire are preferably generated via deterioration and carbonization of the alternating organic naphthalene layers, ${ }^{13}$ which agrees well with the layered crystalline structure of the MOF (Figure S2). The highresolution transmission electron microscopy (HRTEM) image (Figure 1d) presents apparently different domains of amorphous carbon and crystalline $\mathrm{Co}_{3} \mathrm{O}_{4}$, with clearly identified lattice fringe space of $2.4 \AA$ corresponding to the (311) plane of cubic $\mathrm{Co}_{3} \mathrm{O}_{4}$ spinel-phase. Notably, Co species catalyze the formation of partially graphitized carbon on the surface of $\mathrm{Co}_{3} \mathrm{O}_{4}$. The HRTEM observation is also consistent with the uniform dispersion of $\mathrm{Co}$ and $\mathrm{C}$ elements in $\mathrm{Co}_{3} \mathrm{O}_{4} \mathrm{C}-\mathrm{NA}$ (energy dispersive $\mathrm{X}$-ray spectroscopy (EDS) elemental mapping image, Figures 1e, f), together verifying the homogeneous distribution of closely interconnected $\mathrm{Co}_{3} \mathrm{O}_{4}$ and carbon species. 
(a)
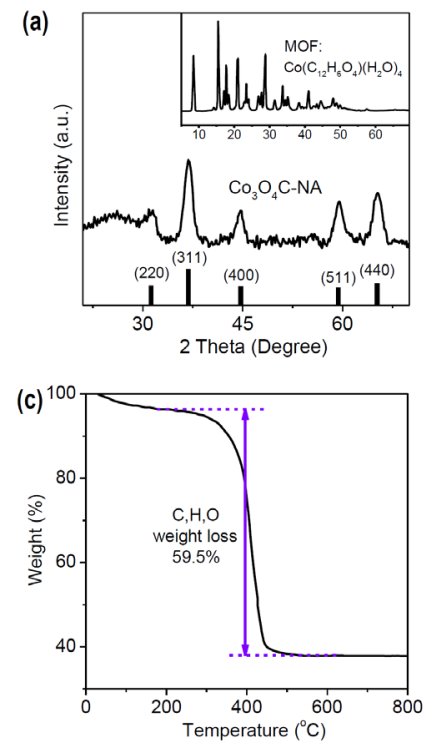

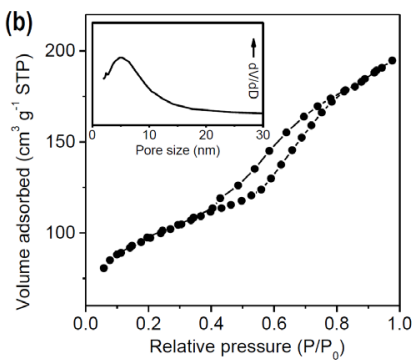

(d)

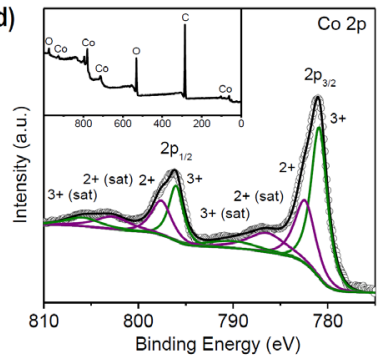

Figure 2. XRD patterns of (a) $\mathrm{Co}_{3} \mathrm{O}_{4} \mathrm{C}-\mathrm{NA}$ and (inset in panel a) the MOF used as the precursor. (b) $\mathrm{N}_{2}$ adsorption isotherm and (inset in panel b) the corresponding pore size distribution of $\mathrm{Co}_{3} \mathrm{O}_{4} \mathrm{C}-\mathrm{NA}$. (c) $\mathrm{TG}$ curve of $\mathrm{Co}_{3} \mathrm{O}_{4} \mathrm{C}-\mathrm{NA}$. (d) High-resolution XPS spectrum of Co $2 p$ core level and (inset in panel d) XPS survey spectrum of $\mathrm{Co}_{3} \mathrm{O}_{4} \mathrm{C}-\mathrm{NA}$.

The multiple peaks on the X-ray diffraction (XRD) pattern of the Co-based MOF used (inset in Figure 2a) well match those of the typical crystalline structure of $\mathrm{Co}\left(\mathrm{C}_{12} \mathrm{H}_{6} \mathrm{O}_{4}\right)\left(\mathrm{H}_{2} \mathrm{O}\right)_{4},{ }^{14}$ without detectable peaks from cobalt oxides. After carbonization, $\mathrm{Co}_{3} \mathrm{O}_{4} \mathrm{C}-\mathrm{NA}$ exhibits the cubic spinel-phase structure (JCPDS No. 43-1003) with a broad shoulder peak in the range of 20 to $30^{\circ}(2 \theta)$, which is originated from the amorphous carbon species homogeneously distributed in nanowires that are in situ formed during carbonization process (Figure 2a), as evidenced by HRTEM and EDS. The $\mathrm{N}_{2}$ adsorption isotherm recorded on $\mathrm{Co}_{3} \mathrm{O}_{4} \mathrm{C}$-NA resembles type IV with a $\mathrm{H} 3$ type hysteresis loop (Figure 2b), commonly observed for materials with slit-like mesopores, ${ }^{15}$ which agrees well with TEM observation and the layered crystalline structure of the MOF used. Correspondingly, one peak centered at $\sim 5 \mathrm{~nm}$ is found in the pore size distribution curve. Also, $\mathrm{Co}_{3} \mathrm{O}_{4} \mathrm{C}-\mathrm{NA}$ displays a large surface area of $251 \mathrm{~m}^{2} \mathrm{~g}^{-1}$, which is much higher than that of the Co-based MOF used (Figure S3) and other reported nanowire arrays prepared by inorganic precursors (up to $\sim 100 \mathrm{~m}^{2} \mathrm{~g}^{-1}$ ), ${ }^{7,9-11}$ indicating the superiority of our proposed method for creating highly porous hybrid nanowires from MOF via the carbonization process.

The hybrid nature of nanowire arrays was further confirmed by thermogravimetric analysis (TG, Figure 2c). Besides the $3 \%$ weight loss below $200{ }^{\circ} \mathrm{C}$ due to the adsorbed water and gases, the weight loss of $59.5 \%$ in $\mathrm{Co}_{3} \mathrm{O}_{4} \mathrm{C}$-NA between 200 to $500{ }^{\circ} \mathrm{C}$ is ascribed to the combustion of carbon species with some surface-bonded oxygen-containing functional groups, which is consistent with the elemental analysis showing the carbon content of 52.1 wt.\%. X-ray photoelectron spectra (XPS) indicate that $\mathrm{Co}_{3} \mathrm{O}_{4} \mathrm{C}-\mathrm{NA}$ contains $\mathrm{Co}, \mathrm{C}$ and $\mathrm{O}$ elements without other impurities, and the best deconvolution of Co $2 p$ profile was achieved under assumption of eight species including two pairs of spin-orbit doublets indicating the coexistence of $\mathrm{Co}^{2+}$ and $\mathrm{Co}^{3+}$ and their four shake-up satellites (denoted as 'sat', Figure 2d). ${ }^{16}$ As compared to the XPS peak

centered at $780.1 \mathrm{eV}$ assigned to $\mathrm{Co} 2 \mathrm{p}_{3 / 2}$ of pure $\mathrm{Co}_{3} \mathrm{O}_{4}$ (Figure S4), the shift of the corresponding peak of $\mathrm{Co}_{3} \mathrm{O}_{4} \mathrm{C}-\mathrm{NA}$ to $781.2 \mathrm{eV}$ implies the close assembly and strong interaction between $\mathrm{Co}_{3} \mathrm{O}_{4}$ and carbon, resulting in the impaired electron density of $\mathrm{Co}$ atoms in $\mathrm{Co}_{3} \mathrm{O}_{4} \mathrm{C}-\mathrm{NA} .{ }^{17}$ Therefore, TEM, EDS and XPS demonstrate homogenously dispersed and well interacting nanocrystalline $\mathrm{Co}_{3} \mathrm{O}_{4}$ and conductive carbon species in $\mathrm{Co}_{3} \mathrm{O}_{4} \mathrm{C}-\mathrm{NA}$, which is desired for high-performance electrocatalysts.

\subsection{OXYGEN EVOLUTION ACTIVITY}
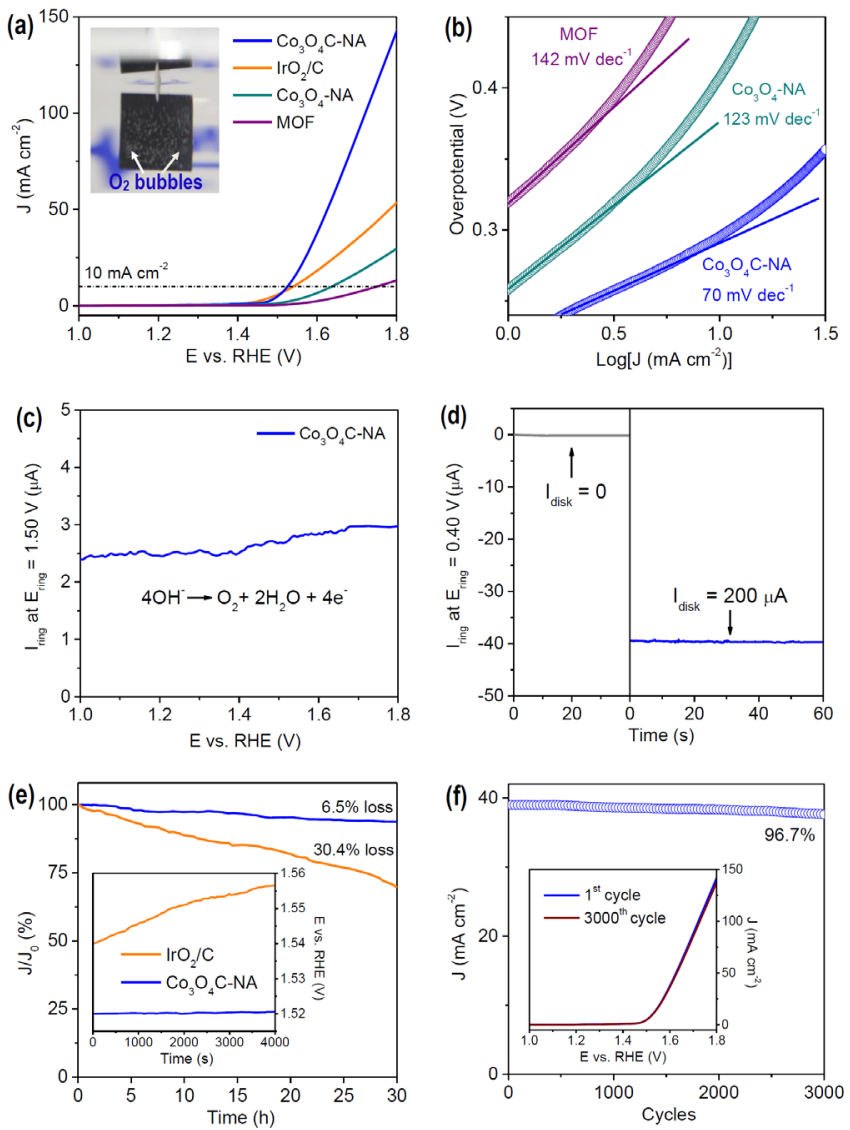

Figure 3. (a) Polarization curves and (b) Tafel plots of $\mathrm{Co}_{3} \mathrm{O}_{4} \mathrm{C}-$ $\mathrm{NA}, \mathrm{IrO}_{2} / \mathrm{C}, \mathrm{Co}_{3} \mathrm{O}_{4}-\mathrm{NA}$, and the MOF in an $\mathrm{O}_{2}$-saturated $0.1 \mathrm{M}$ $\mathrm{KOH}$ solution (scan rate: $0.5 \mathrm{mV} \mathrm{s}^{-1}$ ). (Inset in panel a) An optical image of $\mathrm{Co}_{3} \mathrm{O}_{4} \mathrm{C}$-NA directly used as the OER electrode operating at $1.70 \mathrm{~V}$ with generated bubbles on the surface indicating the formation of $\mathrm{O}_{2}$ gas. (c) The ring current of $\mathrm{Co}_{3} \mathrm{O}_{4} \mathrm{C}-\mathrm{NA}$ on a $\operatorname{RRDE}(1500 \mathrm{rpm})$ in $\mathrm{O}_{2}$-saturated $0.1 \mathrm{M} \mathrm{KOH}$ solution (ring potential: $1.50 \mathrm{~V})$. (d) The ring current of $\mathrm{Co}_{3} \mathrm{O}_{4} \mathrm{C}-\mathrm{NA}$ on a $\operatorname{RRDE}(1500 \mathrm{rpm})$ in $\mathrm{N}_{2}$-saturated $0.1 \mathrm{M} \mathrm{KOH}$ solution (ring potential: $0.40 \mathrm{~V})$. (e) Chronoamperometric response at a constant potential of $1.52 \mathrm{~V}\left(E_{\mathrm{j}=10}\right)$, and (inset in panel e) chronopotentiometric response at a constant current density of $10.0 \mathrm{~mA} \mathrm{~cm}{ }^{-2}$ of $\mathrm{Co}_{3} \mathrm{O}_{4} \mathrm{C}-\mathrm{NA}$ as compared to that of $\mathrm{IrO}_{2} / \mathrm{C}$. (f) A plot of the current density at $1.60 \mathrm{~V}$ recorded from the polarization curve of $\mathrm{Co}_{3} \mathrm{O}_{4} \mathrm{C}$-NA $v s$. the cycle number, and (inset in panel f) polarization curves of $\mathrm{Co}_{3} \mathrm{O}_{4} \mathrm{C}-\mathrm{NA}$ before and after 3000 potential cycles (scan rate: $100 \mathrm{mV} \mathrm{s}^{-1}$ ).

Sizable and shapeable electrodes can be prepared by simply tailoring the $\mathrm{Cu}$ foil, and the obtained $\mathrm{Co}_{3} \mathrm{O}_{4} \mathrm{C}-\mathrm{NA}$ grown on $\mathrm{Cu}$ foil can be directly used as the working electrode for OER (Figures 3a inset, S5, Video S1) without employing extra substrates (e.g. glassy carbon electrode) or binders (e.g. 
nafion). A slow scan rate $\left(0.5 \mathrm{mV} \mathrm{s}^{-1}\right)$ was applied during the OER test to minimize the capacitive current. Since $\mathrm{Co}_{3} \mathrm{O}_{4}$ nanocrystals may partially dissolve in acidic solutions such as $\mathrm{H}_{2} \mathrm{SO}_{4}$, alkaline eletrolytes $(0.1 \mathrm{M}$ and $1.0 \mathrm{M} \mathrm{KOH})$ are prefered for the catalyst studied and examined in this work. The $\mathrm{Cu}$ foil exhibits negligible catalytic activity as shown in the polarization curve conducted in $0.1 \mathrm{M} \mathrm{KOH}$ solution (Figure S6), and the Co-based MOF also displays low OER response with a high onset potential at $\sim 1.55 \mathrm{~V} v s$. reversible hydrogen electrode (RHE, Figure 3a); while the anodic current recorded on $\mathrm{Co}_{3} \mathrm{O}_{4} \mathrm{C}-\mathrm{NA}$ renders a sharp onset potential at $\sim 1.47 \mathrm{~V}$ with greatly enhanced OER current, indicating that the compositional transformation of MOF to hybrid $\mathrm{Co}_{3} \mathrm{O}_{4}$-carbon can significantly improve the catalytic activity. Noticeably, the OER current of $\mathrm{Co}_{3} \mathrm{O}_{4} \mathrm{C}-\mathrm{NA}$ largely exceeds that of $\mathrm{IrO}_{2} / \mathrm{C}$ (coated on $\mathrm{Cu}$ foil with the same loading amount and carbon content to that of $\mathrm{Co}_{3} \mathrm{O}_{4} \mathrm{C}-\mathrm{NA}$, see synthesis details in Supporting Information), despite of the slightly lower onset potential of $\mathrm{IrO}_{2} / \mathrm{C}(\sim 1.45 \mathrm{~V})$, featuring much better catalytic performance of $\mathrm{Co}_{3} \mathrm{O}_{4} \mathrm{C}-\mathrm{NA}$.

We further compared the operating potentials required for different catalysts to deliver a $10.0 \mathrm{~mA} \mathrm{~cm}$-2 current density $\left(E_{\mathrm{j}=10}\right)$, which is a metric related to solar fuel synthesis. ${ }^{18}$ $\mathrm{Co}_{3} \mathrm{O}_{4} \mathrm{C}-\mathrm{NA}$ affords a current density of $10.0 \mathrm{~mA} \mathrm{~cm}{ }^{-2}$ at 1.52 $\mathrm{V}$, lower than that of $\mathrm{IrO}_{2} / \mathrm{C}$ at $1.54 \mathrm{~V}$ and many other reported noble-metal catalysts. ${ }^{3 \mathrm{~b}, 5 \mathrm{c}, 19}$ Moreover, this excellent OER activity of $\mathrm{Co}_{3} \mathrm{O}_{4} \mathrm{C}-\mathrm{NA}$ is not only better than that of most of the state-of-the-art Co-based transition-metal electrocatalysts, ${ }^{4 \mathrm{~d}, \mathrm{e}, 17 \mathrm{a}, 18,20}$ and non-metal catalysts, ${ }^{5}$ but also superior to that of all the nanowire array electrodes reported to date, i.e. $\mathrm{Zn}_{x} \mathrm{Co}_{3-x} \mathrm{O}_{4}$ nanowire arrays grown on Ti foils $(1.55 \mathrm{~V}$, $\mathrm{pH}$ 14), ${ }^{9 \mathrm{a}} \mathrm{Ni}_{x} \mathrm{Co}_{3-x} \mathrm{O}_{4}$ nanowire arrays grown on Ti foils $(\sim 1.60$ $\mathrm{V}, \mathrm{pH} 14),{ }^{9 \mathrm{~b}}$ and $\mathrm{Ni}$-substituted $\mathrm{Co}_{3} \mathrm{O}_{4}$ nanowire arrays grown on $\mathrm{Ni}$ foams $(\sim 1.60 \mathrm{~V}, \mathrm{pH} 14) .{ }^{11} \mathrm{~A}$ detailed comparison of different highly active OER catalyts with various electrode configurations is shown in Table S1, further confirming the outstanding catalytic behavior of $\mathrm{Co}_{3} \mathrm{O}_{4} \mathrm{C}-\mathrm{NA}$. Also, the catalytic kinetics for oxygen evolution was examined by Tafel plots (Figure 3b). The Tafel slope value of $\mathrm{Co}_{3} \mathrm{O}_{4} \mathrm{C}-\mathrm{NA}(70$ $\mathrm{mV}$ decade $\left.^{-1}\right)$ is lower than that of the Co-based MOF (142 $\mathrm{mV}$ decade $\left.{ }^{-1}\right)$ and $\mathrm{IrO}_{2} / \mathrm{C}\left(97 \mathrm{mV}\right.$ decade ${ }^{-1}$, Figure S7), and comparable to that of the previously reported highly active OER catalyts (Table S1), suggesting its favorable reaction kinetics.

To investigate the reaction mechanism, the rotating ringdisk electrode (RRDE) technique was employed with a Pt ring electrode potential of $1.50 \mathrm{~V}$ to oxidize the peroxide intermediates formed at the $\mathrm{Co}_{3} \mathrm{O}_{4} \mathrm{C}$-NA surface during OER. $\mathrm{Co}_{3} \mathrm{O}_{4} \mathrm{C}$-NA was scraped off from $\mathrm{Cu}$ foil and coated on a RRDE (see experimental details in Supporting Information). As shown in Figure 3c, a very low ring current ( $\mu \mathrm{A}$ scale) was detected, which is three orders of magnitude lower than that of the disk current ( $\mathrm{mA}$ scale), suggesting negligible hydrogen peroxide formation and therefore a desirable four-electron pathway for water oxidation, i.e. $4 \mathrm{OH}^{-} \rightarrow \mathrm{O}_{2}+2 \mathrm{H}_{2} \mathrm{O}+4 \mathrm{e}^{-}$. Furthermore, to confirm that the observed current originates from water oxidation rather than other side reactions and to calculate the Faradaic efficiency, a RRDE with the ring potential of $0.40 \mathrm{~V}$ was applied to reduce the generated $\mathrm{O}_{2}$, rendering a continuous OER (disk electrode) $\rightarrow$ ORR (ring electrode) process (Figure S8). With the disk current held constantly at $200 \mu \mathrm{A}, \mathrm{O}_{2}$ molecules generated from the $\mathrm{Co}_{3} \mathrm{O}_{4} \mathrm{C}-\mathrm{NA}$ catalyst surface on the disk electrode sweep across the surrounding Pt ring electrode that is held at an ORR potential, and are rapidly reduced. Consequently, a ring current of $\sim 39.7 \mu \mathrm{A}$ (collection efficiency $=0.2$ ) was detected (Figure 3d), which verifies the observed oxidation current catalyzed by $\mathrm{Co}_{3} \mathrm{O}_{4} \mathrm{C}-\mathrm{NA}$ can be fully attributed to OER with a high Faradaic efficiency of $99.3 \%$ (see detailed calculation in Supporting Information).

Strong durability toward OER is of great significance for energy conversion and storage systems. The chronoamperometric response demonstrates the high stability of $\mathrm{Co}_{3} \mathrm{O}_{4} \mathrm{C}-\mathrm{NA}$, showing slight anodic current attenuation of $6.5 \%$ within 30 hours, whereas $\mathrm{IrO}_{2} / \mathrm{C}$ displays a 4.7 times larger current attenuation of $30.4 \%$ (Figures 3e, S9), indicating the apparent advantage of active materials directly grown on conductive substrates as compared to the postcoated catalysts on electrodes, because the latter suffer from peeling off during the evolution of a large amount of $\mathrm{O}_{2}$ gas. ${ }^{3-5}$ The XRD pattern of the catalyst after 30-hour reaction shows no phase change as compared to the fresh $\mathrm{Co}_{3} \mathrm{O}_{4} \mathrm{C}-\mathrm{NA}$ (Figure S10), which corroborates that the hybrid $\mathrm{Co}_{3} \mathrm{O}_{4}$ carbon nanowire arrays act as highly OER-active and stable catalysts. In the chronopotentiometric response, $\mathrm{Co}_{3} \mathrm{O}_{4} \mathrm{C}-\mathrm{NA}$ affords a nearly constant operating potential of $1.52 \mathrm{~V}$ to deliver a $10.0 \mathrm{~mA} \mathrm{~cm}{ }^{-2}$ current density (Figure 3e inset), whereas the potential of $\mathrm{IrO}_{2} / \mathrm{C}$ increases for $>15 \mathrm{mV}$ within $4000 \mathrm{~s}$, again revealing the stronger durability of $\mathrm{Co}_{3} \mathrm{O}_{4} \mathrm{C}-\mathrm{NA}$. Further, only $3.3 \%$ anodic current loss was observed for $\mathrm{Co}_{3} \mathrm{O}_{4} \mathrm{C}$-NA after 3000 continuous potential cyclings at an accelerated scanning rate of $100 \mathrm{mV} \mathrm{s}^{-1}$ (Figure 3f), confirming the catalyst is also highly stable to withstand accelerated degradation.

The effective operation of electrocatalysts in concentrated electrolytes is a critical figure of merit for practical applications. ${ }^{18}$ In $1.0 \mathrm{M} \mathrm{KOH}$, the high activity of $\mathrm{Co}_{3} \mathrm{O}_{4} \mathrm{C}-\mathrm{NA}$ is well preserved showing larger current density, and much lower Tafel slope of $61 \mathrm{mV}$ decade ${ }^{-1}$ than that of $\mathrm{IrO}_{2} / \mathrm{C}(87$ $\mathrm{mV}$ decade $^{-1}$, Figures S11a, b), indicating the superior reaction kinetics of $\mathrm{Co}_{3} \mathrm{O}_{4} \mathrm{C}-\mathrm{NA}$. Both the chronoamperometric and chronopotentiometric responses show much smaller OER activity attenuation of $\mathrm{Co}_{3} \mathrm{O}_{4} \mathrm{C}-\mathrm{NA}$ in comparison to that of $\mathrm{IrO}_{2} / \mathrm{C}$ (Figures S11c, d), demonstrating the strong durability of $\mathrm{Co}_{3} \mathrm{O}_{4} \mathrm{C}-\mathrm{NA}$ in concentrated alkaline solutions.

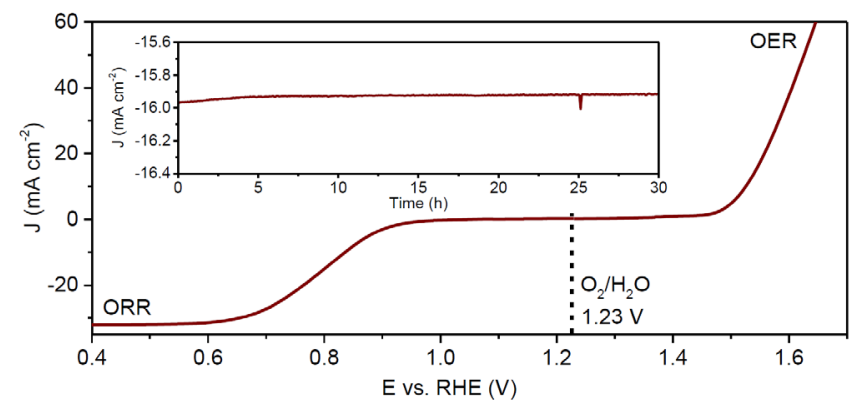

Figure 4. Polarization curve measured in $\mathrm{O}_{2}$-saturated $0.1 \mathrm{M}$ $\mathrm{KOH}$ solution (scan rate: $0.5 \mathrm{mV} \mathrm{s}^{-1}$ ) for $\mathrm{Co}_{3} \mathrm{O}_{4} \mathrm{C}$-NA grown on $\mathrm{Cu}$ foil (directly used as the working electrode) in the whole region of OER and ORR. (Inset in the panel) chronoamperometric response of $\mathrm{Co}_{3} \mathrm{O}_{4} \mathrm{C}-\mathrm{NA}$ at a constant potential of $0.78 \mathrm{~V}\left(E_{1 / 2}\right)$, with methanol addition after $25 \mathrm{~h}$.

The reaction reversibility initiated on an oxygen evolution electrode, which can also efficiently catalyze the reverse ORR 
process, is of significant importance, especially for rechargeable metal-air batteries and regenerated fuel cells involving these two reactions. Thus, polarization curves were recorded in the whole region of OER and ORR. In ORR region, $\mathrm{Co}_{3} \mathrm{O}_{4} \mathrm{C}-\mathrm{NA}$ exhibits a half-wave potential $\left(E_{1 / 2}\right)$ of $0.78 \mathrm{~V}$ (Figure 4) and Tafel slope of $89 \mathrm{mV} \mathrm{decade}^{-1}$ (Figure S12a). The overall oxygen electrode activity can be evaluated by the difference of OER and ORR metrics $\left(\Delta E=E_{\mathrm{j}=10}-E_{1 / 2}\right)$. The smaller $\Delta E$ is, the closer the catalyst is to an ideal reversible oxygen electrode. ${ }^{21} \mathrm{Co}_{3} \mathrm{O}_{4} \mathrm{C}$-NA exhibits a $\Delta E$ value of 0.74 $\mathrm{V}$, lower than that of the recently reported highly active reversible oxygen electrodes, e.g. CoO/N-doped graphene $(\Delta E=$ $0.76 \mathrm{~V}),{ }^{20 \mathrm{a}} \mathrm{Co}_{3} \mathrm{O}_{4} / \mathrm{N}$-doped carbon $(\Delta E=0.86 \mathrm{~V})^{21 \mathrm{a}}$ and $\mathrm{H}-$ $\mathrm{Pt} / \mathrm{CaMnO}_{3}(\Delta E=1.01 \mathrm{~V}),{ }^{21 \mathrm{~b}}$ corroborating the excellent reversible oxygen electrode nature of $\mathrm{Co}_{3} \mathrm{O}_{4} \mathrm{C}-\mathrm{NA}$. Further, combining RRDE measurements that suggest an electron transfer number of 3.85-3.96 (from $0.40 \mathrm{~V}$ to $0.90 \mathrm{~V}$ ) for the ORR process (Figure S12b), $\mathrm{Co}_{3} \mathrm{O}_{4} \mathrm{C}-\mathrm{NA}$ favors a desirable four-electron pathway for reversible OER and ORR. Moreover, $\mathrm{Co}_{3} \mathrm{O}_{4} \mathrm{C}$-NA shows a strong durability for ORR as revealed by the chronoamperometric response (Figure 4 inset), delivering a nearly constant current density within 30 hours. Notably, the current density of $\mathrm{Co}_{3} \mathrm{O}_{4} \mathrm{C}$-NA shows no obvious change even after the addition of methanol, indicating its high selectivity to ORR with strong methanol tolerance ability, which can avoid the poisoning cross-over effect, displaying an important quality for cathode materials in low-temperature fuel cells.

\subsection{DISCCUSION}

The unique hybrid nanowire composition and novel electrode configuration endow $\mathrm{Co}_{3} \mathrm{O}_{4} \mathrm{C}$-NA with much better catalytic performance than conventional electrode materials. First, the in situ incorporation of carbon into $\mathrm{Co}_{3} \mathrm{O}_{4} \mathrm{C}-\mathrm{NA}$ assured by the use of MOF as the precursor, leads to the structure with strongly interacting $\mathrm{Co}_{3} \mathrm{O}_{4}$ and carbon species (as evidenced by TEM, EDS and XPS), and highly improved conductivity and charge transfer capability, which favor the high OER activity and stability. For the purpose of comparison, a carbonfree counterpart was prepared by calcination of $\mathrm{Co}_{3} \mathrm{O}_{4} \mathrm{C}-\mathrm{NA}$ in air to eliminate carbon species (denoted as $\mathrm{Co}_{3} \mathrm{O}_{4}-\mathrm{NA}$, see synthesis details in Supporting Information), which also exhibits porous nanowire array structure and cubic spinel phase (Figures S3, S13), but affords higher onset potential of 1.50 $\mathrm{V}$, larger operating potential of $1.64 \mathrm{~V}$ to deliver a $10.0 \mathrm{~mA}$ $\mathrm{cm}^{-2}$ current density (Figure 3a), and higher Tafel slope of $123 \mathrm{mV}$ decade ${ }^{-1}$ (Figure 3b) than those of $\mathrm{Co}_{3} \mathrm{O}_{4} \mathrm{C}-\mathrm{NA}$, suggesting its much lower OER activity with inferior reaction kinetics. Also, the semicircle diameter in the electrochemical impedance spectrum (EIS) of $\mathrm{Co}_{3} \mathrm{O}_{4}$-NA is much larger than that of $\mathrm{Co}_{3} \mathrm{O}_{4} \mathrm{C}-\mathrm{NA}$ due to smaller contact and charge transfer impedance in $\mathrm{Co}_{3} \mathrm{O}_{4} \mathrm{C}$-NA (Figure 5a). Notably, $\mathrm{Co}_{3} \mathrm{O}_{4} \mathrm{C}-\mathrm{NA}$ also largely exceeds the physically mixed $\mathrm{Co}_{3} \mathrm{O}_{4}$-NA and carbon powder in OER performance (Figure $\mathbf{5 b}$, see synthesis details in Supporting Information), which implies that the outstanding activity of $\mathrm{Co}_{3} \mathrm{O}_{4} \mathrm{C}-\mathrm{NA}$ with low resistance originates not simply from the increased electrical conductivity, but also from a complex synergistic effect between strongly interacting $\mathrm{Co}_{3} \mathrm{O}_{4}$ and carbon species. ${ }^{17}$ For instance, the in situ incorporated carbon causes the impaired electron density of Co atoms (as evidenced by XPS), which can make the catalytically active species (i.e. Co) more electrophilic, thus facilitating the adsorption and reaction of $\mathrm{OH}^{-}$groups with $\mathrm{Co}_{3} \mathrm{O}_{4} \mathrm{C}-\mathrm{NA}$, resulting in enhanced OER activity in alkaline solutions. ${ }^{22}$
Second, the mesoporous nanowire arrays afford a large active surface area, which was evaluated by the electrochemical double layer capacitance $\left(\mathrm{C}_{\mathrm{dl}}\right)$ and surface roughness factor $\left(\mathrm{R}_{\mathrm{f}}\right)$. By calculating the slope from the linear relationship of the current density against the scan rate (see calculation details in Supporting Information), $\mathrm{C}_{\mathrm{dl}}$ of $\mathrm{Co}_{3} \mathrm{O}_{4} \mathrm{C}$ $\mathrm{NA}$ is confirmed to be $209.7 \mathrm{mF} \mathrm{cm} \mathrm{cm}^{-2}$ with a $\mathrm{R}_{\mathrm{f}}$ of 3495 (Figure 5c), which is much higher than that of $\mathrm{IrO}_{2} / \mathrm{C}\left(\mathrm{C}_{\mathrm{dl}}=\right.$ $22.3 \mathrm{mF} \mathrm{cm}^{-2}, R_{\mathrm{f}}=371$, Figure S14). Since $C_{d l}$ and $R_{f}$ are proportional to the active surface area of electrocatalysts, ${ }^{7-11}$ the results demostrate mesoporous nanowire arrays directly grown on $\mathrm{Cu}$ foil are more effective in enlarging the catalytically active surface area as compared to conventioanl planar catalyst films coated on electrodes; thus, better exposure and enhanced utilization of electroactive sites (e.g. $\mathrm{Co}$ species) on the large active surface of $\mathrm{Co}_{3} \mathrm{O}_{4} \mathrm{C}$-NA greatly contribute to its ultrahigh OER activity.

Third, the reaction kinetics for OER is significantly promoted by the advanced electrode configuration. The nanowire arrays provide smooth pathway for fast penetration of electrolyte, while the mesopores facilitate the access of reactants $\left(e . g . \mathrm{OH}^{-}\right)$in the electrolyte to the active sites within nanowires, as well as the fast emission of reaction products (e.g. $\mathrm{O}_{2}$ ). Accordingly, $\mathrm{Co}_{3} \mathrm{O}_{4} \mathrm{C}-\mathrm{NA}$ displays much smaller Tafel slope than that of $\mathrm{IrO}_{2} / \mathrm{C}$, physically mixed $\mathrm{Co}_{3} \mathrm{O}_{4}-\mathrm{NA}$ and carbon powder, and other catalysts in the control group (Figures 3b, 5b inset, S7, S11b), indicating its more favorable reaction kinetics. Also, its current density in OER potential region is insusceptible to the scan rate, showing a variation of $3.5 \%$ (vs. $14.3 \%$ of $\mathrm{IrO}_{2} / \mathrm{C}$ ) with increasing the scan rate from $0.5 \mathrm{mV} \mathrm{s}^{-1}$ to $50 \mathrm{mV} \mathrm{s}^{-1}$ (Figure $\mathbf{S 1 5}$ ), due to the improved mass transport in the mesoporous nanowire arrays. ${ }^{5,7}$ Additionally, the micro-structure of nanowire arrays is believed to promote the release of evolved $\mathrm{O}_{2}$ gas bubbles (Video S1), by effectively bursting larger $\mathrm{O}_{2}$ bubbles that commonly stick to the planar catalyst film surface, and wicking the evolved bubbles to maintain the solid-liquid interface. $^{23}$
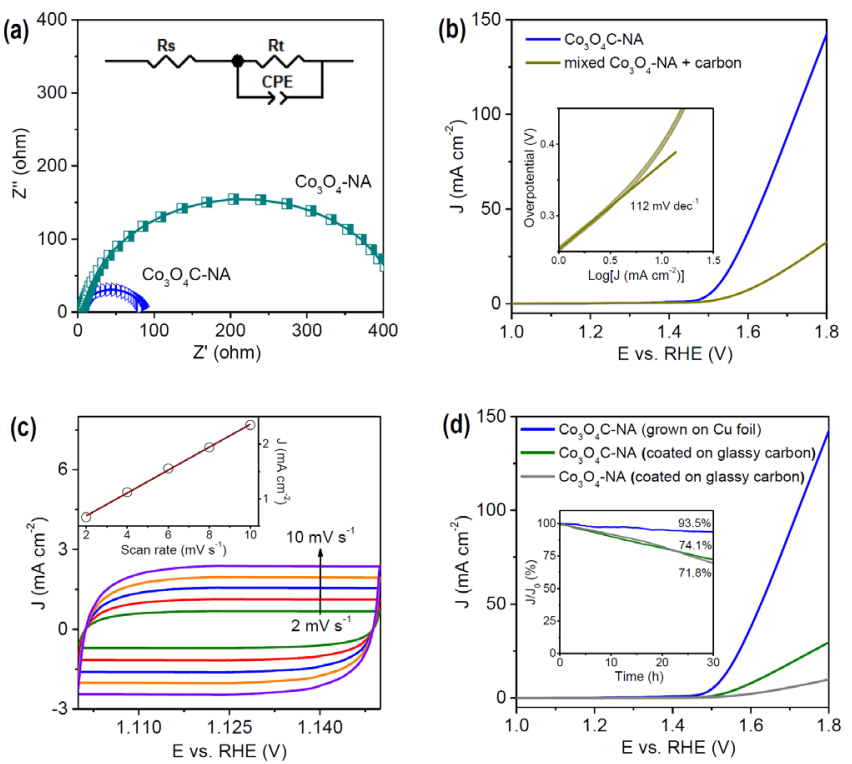

Figure 5. (a) EIS of $\mathrm{Co}_{3} \mathrm{O}_{4} \mathrm{C}-\mathrm{NA}$ and $\mathrm{Co}_{3} \mathrm{O}_{4}-\mathrm{NA}$ recorded at 1.60 $\mathrm{V}$, and (inset in panel a) the corresponding equivalent circuit diagram consisting of an electrolyte resistance (Rs), a charge-transfer resistance (Rt) and a constant-phase element (CPE). (b) Polariza- 
tion curves of $\mathrm{Co}_{3} \mathrm{O}_{4} \mathrm{C}-\mathrm{NA}$ directly grown on $\mathrm{Cu}$ foil and physically mixed $\mathrm{Co}_{3} \mathrm{O}_{4}-\mathrm{NA}$ and carbon powder coated on $\mathrm{Cu}$ foil, and (inset in panel b) Tafel plot of the physically mixed $\mathrm{Co}_{3} \mathrm{O}_{4}-\mathrm{NA}$ and carbon powder. (c) Cyclic voltammograms (CVs) of $\mathrm{Co}_{3} \mathrm{O}_{4} \mathrm{C}-$ NA measured at different scan rates from 2 to $10 \mathrm{mV} \mathrm{s}^{-1}$, and (inset in panel c) a plot of the current density at $1.14 \mathrm{~V} v s$. the scan rate. (d) Polarization curves of $\mathrm{Co}_{3} \mathrm{O}_{4} \mathrm{C}-\mathrm{NA}$ directly grown on $\mathrm{Cu}$ foil, $\mathrm{Co}_{3} \mathrm{O}_{4} \mathrm{C}-\mathrm{NA}$ and $\mathrm{Co}_{3} \mathrm{O}_{4}-\mathrm{NA}$ scraped off from $\mathrm{Cu}$ foil and coated on glassy carbon electrodes, and (inset in panel d) the corresponding chronoamperometric response at a constant potential of $1.52 \mathrm{~V}$.

Last but not least, the direct growth of active materials on the conductive $\mathrm{Cu}$ foil can greatly enhance the electron transport and adhesion between nanowire arrays and substrates, promote the structural stability for long-term usage, and avoid utilization of polymeric binders and extra conductive additives, consequently reducing the dead volume and undesirable interface in the electrode, ${ }^{9-11,12 b}$ which is corroborated by the much higher OER activity and stronger durability of $\mathrm{Co}_{3} \mathrm{O}_{4} \mathrm{C}$ NA than those of $\mathrm{IrO}_{2} / \mathrm{C}$ coated on $\mathrm{Cu}$ foil (Figure 3e), and those of $\mathrm{Co}_{3} \mathrm{O}_{4}-\mathrm{NA}$ and $\mathrm{Co}_{3} \mathrm{O}_{4} \mathrm{C}$-NA scraped off from $\mathrm{Cu}$ foil and coated on traditional glassy carbon electrodes (Figure 5d). Also, even operating at a high potential of $1.80 \mathrm{~V}$ (delivering a very large current density of $\left.\sim 140 \mathrm{~mA} \mathrm{~cm}{ }^{-2}\right), \mathrm{Co}_{3} \mathrm{O}_{4} \mathrm{C}-\mathrm{NA}$ shows no visible peeling from $\mathrm{Cu}$ foil (Video S1), suggesting the strong stability of this type of oxygen evolution electrodes.

\section{CONCLUSIONS}

In summary, hybrid $\mathrm{Co}_{3} \mathrm{O}_{4}$-carbon porous nanowire arrays directly grown on $\mathrm{Cu}$ foil exhibit higher OER activity, more favorable kinetics and stronger durability than those of $\mathrm{IrO}_{2} / \mathrm{C}$. The OER performance is the best among all the reported nanowire array electrodes, and better than most of the highly active noble-/transition-metal and non-metal OER catalysts, which can be attributed to the porous nanowire array electrode configuration and in situ carbon incorporation, leading to enlarged active surface area, strong structural stability, and improved mass/charge transport. Considering their capability for catalyzing ORR through an efficient four-electron pathway, these brand new reversible oxygen electrodes are promising to be directly used in metal-air batteries, fuel cells, water splitting devices and other key renewable energy systems.

\section{ASSOCIATED CONTENT}

Supporting Information. Experimental details; SEM images, crystalline structure with the CIF file and $\mathrm{N}_{2}$ adsorption of the Cobased MOF; XPS, XRD, SEM images and N2 adsorption of $\mathrm{Co}_{3} \mathrm{O}_{4}-\mathrm{NA}$; optical photos of three-electrode OER testing cells; OER activity and stability tests of $\mathrm{Co}_{3} \mathrm{O}_{4} \mathrm{C}-\mathrm{NA}$ in $1.0 \mathrm{M}$ $\mathrm{KOH}$; polarization curves, Tafel plots and stability tests of control groups; Tafel plot, electron transfer number and $\mathrm{HO}_{2}{ }^{-}$ production curves for ORR of $\mathrm{Co}_{3} \mathrm{O}_{4} \mathrm{C}-\mathrm{NA}$; a detailed comparisom of various OER catalysts; and a video of $\mathrm{Co}_{3} \mathrm{O}_{4} \mathrm{C}$ NA working at different operating potentials. This material is available free of charge via the Internet at http://pubs.acs.org.

\section{AUTHOR INFORMATION}

\section{Corresponding Author}

*E-mail: s.qiao@adelaide.edu.au

\section{Author Contributions}

All authors have given approval to the final version of the manuscript.

\section{Notes}

The authors declare no competing financial interest.

\section{ACKNOWLEDGMENT}

This work is financially supported by the Australian Research Council (ARC) through the Discovery Project programs (DP140104062 and DP130104459).

\section{REFERENCES}

1. a) Kim, T. W.; Choi, K. S. Science 2014, 343, 990-994; b) Zhang, M.; de Respinis, M.; Frei, H. Nat. Chem. 2014, 6, 362-367; c) Yuan, C. Z.; Wu, H. B.; Xie, Y.; Lou, X. W. Angew. Chem. 2014, 126, 1512-1530; Angew. Chem. Int. Ed. 2014, 53, 1488-1504.

2. a) Katsounaros, I.; Cherevko, S.; Zeradjanin, A. R.; Mayrhofer, K. J. J. Angew. Chem. 2014, 126, 104-124; Angew. Chem. Int. Ed. 2014, 53, 102-121; b) Oh, S. H.; Black, R.; Pomerantseva, E.; Lee, J. H.; Nazar, L. F. Nat. Chem. 2012, 4, 1004-1010.

3. a) Over, H. Chem. Rev. 2012, 112, 3356-3426; b) Lee, Y.; Suntivich, J.; May, K. J.; Perry, E. E.; Shao-Horn, Y. J. Phys. Chem. Lett. 2012, 3, 399-404.

4. a) Jin, K.; Park, J.; Lee, J.; Yang, K. D.; Pradhan, G. K.; Sim, U.; Jeong, D.; Jang, H. L.; Park, S.; Kim, D.; Sung, N. E.; Kim, S. H.; Han, S.; Nam, K. T. J. Am. Chem. Soc. 2014, 136, 7435-7443; b) Gong, M.; Li, Y. G.; Wang, H. L.; Liang, Y. Y.; Wu, J. Z.; Zhou, J. G.; Wang, J.; Regier, T.; Wei, F.; Dai, H. J. J. Am. Chem. Soc. 2013, 135, 8452-8455; c) Subbaraman, R.; Tripkovic, D.; Chang, K. C.; Strmcnik, D.; Paulikas, A. P.; Hirunsit, P.; Chan, M.; Greeley, J.; Stamenkovic, V.; Markovic, N. M. Nat. Mater. 2012, 11, 550-557; d) Gao, M. R.; Xu, Y. F.; Jiang, J.; Zheng, Y. R.; Yu, S. H. J. Am. Chem. Soc. 2012, 134, 2930-2933; e) Liang, Y. Y.; Li, Y. G.; Wang, H. L.; Zhou, J. G.; Wang, J.; Regier, T.; Dai, H. J. Nat. Mater. 2011, 10, 780-786

5. a) Ma, T. Y.; Dai, S.; Jaroniec, M.; Qiao, S. Z. Angew. Chem. 2014, 126, 7409-7413; Angew. Chem. Int. Ed. 2014, 53, 72817285; b) Tian, G. L.; Zhao, M. Q.; Yu, D.; Kong, X. Y.; Huang, J. Q.; Zhang, Q.; Wei, F. Small 2014, 10, 2251-2259; c) Zhao, Y.; Nakamura, R.; Kamiya, K.; Nakanishi, S.; Hashimoto, K. Nat. Commun. 2013, 4, 2390; d) Park, H. W.; Lee, D. U.; Liu, Y.; Wu, J.; Nazar, L. F.; Chen, Z. J. Electrochem. Soc. 2013, 160, A2244-A2250.

6. a) Wang, J.; Zhong, H. X.; Qin, Y. L.; Zhang, X. B. Angew. Chem. 2013, 125, 5356-5361; Angew. Chem. Int. Ed. 2013, 52, 5248-5253; b) Xin, S.; Guo, Y. G.; Wan, L. J. Acc. Chem. Res. 2012, 45, 1759-1769; c) Cheng, F. Y.; Chen, J. Chem. Soc. Rev. 2012, 41, 2172-2192; d) Kibsgaard, J.; Gorlin, Y.; Chen, Z.; Jaramillo, T. F. J. Am. Chem. Soc. 2012, 134, 7758-7765; e) Lang, X. Y.; Hirata, A.; Fujita, T.; Chen, M. W. Nat. Nanotechnol. 2011, 6, 232-236.

7. a) Wang, K.; Wu, H.; Meng, Y.; Wei, Z. Small 2014, 10, 14 31; b) Shen, L.; Che, Q.; Li, H.; Zhang, X. Adv. Funct. Mater. 2014, 24, 2630-2637; c) Jiang, Y.; Zhang, X.; Ge, Q. Q.; Yu, B. B.; Zou, Y. G.; Jiang, W. J.; Song, W. G.; Wan, L. J.; Hu, J. S. Nano Lett. 2014, 14, 365-372; d) Tian, J. Q.; Liu, Q.; Asiri, A. M.; Sun, X. P. J. Am. Chem. Soc. 2014, 136, 7587-7590; e) Liao, J. Y.; Higgins, D.; Lui, G.; Chabot, V.; Xiao, X.; Chen, Z. Nano Lett. 2013, 13, 5467-5473; f) Yuan, C.; Yang, L.; Hou, L.; Shen, L.; Zhang, X.; Lou, X. W. Energy Environ. Sci. 2012, $5,7883-7887$.

8. a) Jiang, J.; Li, Y.; Liu, J.; Huang, X.; Yuan, C.; Lou, X. W. Adv. Mater. 2012, 24, 5166-5180; b) Gong, K.; Du, F.; Xia, Z.; Durstock, M.; Dai, L. M. Science 2009, 323, 760-764.

9. a) Liu, X. J.; Chang, Z.; Luo, L.; Xu, T. H.; Lei, X. D.; Liu, J. F.; Sun, X. M. Chem. Mater. 2014, 26, 1889-1895; b) Li, Y.; Hasin, P.; Wu, Y. Adv. Mater. 2010, 22, 1926-1929.

10. Lee, D. U.; Choi, J. Y.; Feng, K.; Park, H. W.; Chen, Z. Adv. Energy Mater. 2014, 4, 1301389. 
11. Lu, B.; Cao, D.; Wang, P.; Wang, G.; Gao, Y. Int. J. Hydrogen Energy 2011, 36, 72-78.

12. a) Artero, V.; Chavarot-Kerlidou, M.; Fontecave, M. Angew. Chem. 2011, 123, 7376-7405; Angew. Chem. Int. Ed. 2011, 50, 7238-7266; b) Cui, B.; Lin, H.; Li, J. B.; Li, X.; Yang, J.; Tao, J. Adv. Funct. Mater. 2008, 18, 1440-1447.

13. a) Sun, J. K.; Xu, Q. Energy Environ. Sci. 2014, 7, 2071-2100; b) Proietti, E.; Jaouen, F.; Lefèvre, M.; Larouche, N.; Tian, J.; Herranz, J.; Dodelet, J. P. Nat. Commun. 2011, 2, 416; c) Furukawa, H.; Cordova, K. E.; O'Keeffe, M.; Yaghi, O. M. Science 2013, 341, 1230444.

14. Kaduk, J. A.; Hanko, J. A. J. Appl. Cryst. 2001, 34, 710-714.

15. Gu, D.; Schüth, F. Chem. Soc. Rev. 2014, 43, 313-344.

16. Banerjee, D.; Jagadeesh, R. V.; Junge, K.; Pohl, M. M.; Radnik, J.; Brückner, A.; Beller, M. Angew. Chem. 2014, 126, 44484452; Angew. Chem. Int. Ed. 2014, 53, 4359-4363.

17. a) Wu, J.; Xue, Y.; Yan, X.; Yan, W.; Cheng, Q.; Xie, Y. Nano Res. 2012, 5, 521-530; b) Li, J.; Tang, S. B.; Lu, L.; Zeng, H. C. J. Am. Chem. Soc. 2007, 129, 9401-9409.

18. McCrory, C. C. L.; Jung, S.; Peters, J. C.; Jaramillo, T. F. J. Am. Chem. Soc. 2013, 135, 16977-16987.

19. Mamaca, N.; Mayousse, E.; Arrii-Clacens, S.; Napporn, T. W.; Servat, K.; Guillet, N.; Kokoh, K. B. Appl. Catal. B: Environ. 2012, 111-112, 376-380.

20. a) Mao, S.; Wen, Z.; Huang, T.; Hou, Y.; Chen, J. Energy Environ. Sci. 2014, 7, 609-616; b) Zou, X.; Goswami, A.; Asefa, T. J. Am. Chem. Soc. 2013, 135, 17242-17245; c) Smith, R. D. L.; Prévot, M. S.; Fagan, R. D.; Trudel, S.; Berlinguette, C. P. J. Am. Chem. Soc. 2013, 135, 11580-11586.

21. a) Masa, J.; Xia, W.; Sinev, I.; Zhao, A.; Sun, Z.; Grützke, S.; Weide, P.; Muhler, M.; Schuhmann, W. Angew. Chem. 2014, 126, 8648-8652; Angew. Chem. Int. Ed. 2014, 53, 8508-8512; b) Han, X. P.; Cheng, F. Y.; Zhang, T. R.; Yang, J. G.; Hu, Y. X.; Chen, J. Adv. Mater. 2014, 26, 2047-2051.

22. Lu, Z.; Wang, H.; Kong, D.; Yan, K.; Hsu, P. C.; Zheng, G.; Yao, H.; Liang, Z.; Sun, X.; Cui, Y. Nat. Commun. 2014, 5, 4345 .

23. a) Kong, D.; Wang, H.; Lu, Z.; Cui, Y. J. Am. Chem. Soc. 2014, 136, 4897-4900; b) Faber, M. S.; Dziedzic, R.; Lukowski, M. A.; Kaiser, N. S.; Ding, Q.; Jin, S. J. Am. Chem. Soc. 2014, 136, 10053-10061. 
Table of Contents (TOC)

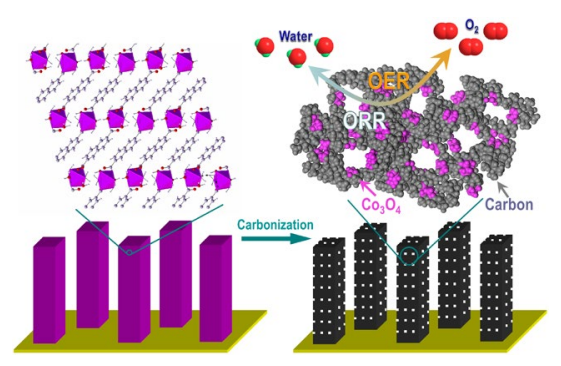

